\title{
Screening of Age-Friendly Criteria by Modified Fuzzy Delphi Method
}

\author{
Sashi Bhusan Raut and Abraham George* \\ Department of Architecture and Regional Planning, India \\ *Corresponding author: Abraham George, Department of Architecture and Regional Planning, West Bengal, Pin-721302, India

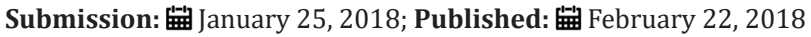

\begin{abstract}
Selection of appropriate and important criteria for a community to measure its 'age-friendliness' has now become very much complex and context specific. This debate has gained momentum globally and specifically for developing countries like India due to rapid increase of proportion of elderly to all age-groups and simultaneous breakdown of traditional joint family system threatening their independence. In a resource scarce setting it is cumbersome to achieve the desired outcome level of all criteria and at one go and therefore needs selection and prioritisation of important ones contributing significantly to the 'age-friendliness index' of the community. The widely used techniques such as 'Delphi', 'Nominal Group Technique' and other similar techniques have their own limitations in this selection process. This study uses 'Modified Fuzzy Delphi' method unlike other methods and proves to be the most scientific one in terms of quantification and selection by a threshold value. It is different from traditional Delphi technique in that 'error level is reduced' using fuzzy sets where quantification of expert's opinion completely reflects their experience. The results showed that criteria identified by this process holds good for evaluating age-friendliness of the community. It also indicated that independent living capability of a person is the most important criteria followed by safety and security of the community environment though other criteria are more or less accountable.
\end{abstract}

Keywords: Age-friendliness; Age-groups; Criteria; Fuzzy Delphi; Threshold

\section{Introduction}

As people age, their physical and mental capacities decline, causing them to fall into poverty, illness, isolation and insecurity. This situation is worse with the breakdown of traditional joint family system to nuclear family system because of migration of youth pushing the elderly to isolation. Their immediate neighbourhood becomes more important for them to remain healthy, active, and socially included. The Idea of Independent living in the continued environment by keeping the neighbourhood wealthy and prosperous has now become the subject of concern. An age-friendly community provides such an environment where all age-groups could stay healthy, socially connected to others, actively participate in the community and have self-esteem. The study led by World Health Organization in 2006 defined the term 'agefriendly' which is unique in its meaning from previous concepts like barrier free, accessible design, inclusive and universal design (WHO [1]). The classification system of WHO in 2002 has shifted from its concept of 'medical model' which interprets disability as a feature of person to 'social model' which results from interaction between person and the environment (Ostroff E [2]). Such an environment adapts its structures and services in enabling people of all ages to stay healthy, socially connected to others, actively participate in the community and feel self-worth which forms an age-friendly community (Government of Queensland [3]). The concept of 'age-friendly community' is developed from a number of policy initiatives implemented by the WHO during the 1990s and early 2000s (Buffel et al. [4]). The age-friendly initiative launched by WHO in 33 cities of 22 countries in 2006 was aimed at identifying age-friendly features, barriers to age-friendliness and suggestions for improvement in age-friendliness and the results obtained interpreted in the form of a checklist of age-friendly features which is a self assessment in the process of making a community agefriendly. Many countries have started this initiative to make their communities age-friendly by incorporating age-friendly features. The developed countries have already taken initiatives to solve aging related issues whereas developing countries are trying to become age-friendly by incorporating age-friendly features. In India this initiative in metropolitan cities like Delhi has found out major issues that work against to make it age-friendly. Also in India the existing acts and policies and amendment of these acts hardly able to address all aging related issues. However it is noted that in developing countries like India where resources are scarce it is cumbersome to achieve the desired outcome level of agefriendliness by incorporating all age-friendly features and at one go. In this context development of an 'age-friendliness index' with the 
help of appropriately identified criteria and sub-criteria along with the level of importance to measure age-friendliness of a community is vital. This in turn helps to classify Indian communities based on their level of 'age-friendliness' and assign priority in Governmental interventions. The normal process of identification of criteria and sub-criteria through literature study, physical survey and validated by the experts serve as a subjective and less scientific in approach. This study uses 'Modified Fuzzy Delphi' method for screening of important criteria by a threshold value through iterative approach followed by fuzzification, defuzzification. 'Modified Fuzzy Delphi' method is a modified form of 'Fuzzy Delphi' method in which error level is reduced using fuzzy sets unlike widely used traditional Delphi method. In this method the quantification of expert's opinion completely reflects their experience. Bhubaneswar Municipal Corporation, in Odisha state of India was chosen as the study area. A focus group discussion was conducted following literature review and pilot study to identify and validate the criteria and sub-criteria for an age-friendly community at an initial stage. Questionnaire was prepared on a seven point Likert scale and modified in each stage of the process based on review and feedback of its previous stage. The experts were asked to rank as well as enlist the missing ones with level of importance in every round after reviewing deviations of their own answers from the mean of opinion of all experts in the previous round. The survey process was repeated by successive rounds until answers converged to a reasonable solution. Experts were chosen from various stakeholders and professionals such as physiotherapist, sociologists, public health experts, architects, social workers, care givers, users, and planners within the study area. The opinions collected from a total of twenty six experts finally were analysed using Fuzzy Delphi method to arrive at important criteria contributing to 'age-friendliness'. Furthermore weights assigned to these criteria and sub-criteria by Analytical Hierarchy Process and subjected to Fuzzy Output Performance Values for different communities by Fuzzy Inference System will determine the 'Age-Friendliness Index' of communities.

\section{Methodology}

The methodology of this paper comprises of four steps which are as follows.

\section{Literature review}

Large amount of literature have been studied to find out agefriendly features of a community. Different terminology, methods and techniques used in different parts of the world to define agefriendliness of a community were studied, classified and tabulated. Various parameters used in the grading process are identified and evaluated in the light of Indian context. WHO's age-friendly city initiative in 2006 across 33 cities in 22 countries gave rise to a checklist of age-friendly features which helped in identifying missing age-friendly features. Simultaneous studies on age-friendly initiatives in cities and in rural areas of other countries also helped in identifying age-friendly features. Those appropriate to the Indian context were identified and retained for the development of the 'Age-friendliness Assessment Tool'. The selection of age-friendly features was subsequently strengthened and validated by 'pilot study' and 'focus group discussion'. Finally age-friendly criteria and sub-criteria relating to these identified features were found out by 'expert opinion survey' and subjected to further analysis in order to establish the hierarchy of importance.

\section{Pilot study}

A pilot study has been conducted to identify age-friendly features from respondents aged 45 years or more. The total number of respondents in this study was thirty, who were the residents of Bhubaneswar Municipal Corporation staying either on rent or on permanent basis. The respondents were asked to respond on the following aspects.

a. Problems faced during stay in home or community.

b. Whether they have anticipated any problem to remain in home or the community for rest of life.

c. Different ways of performing and participating in social activities.

d. Satisfaction level towards community environment.

e. Safety, security and emergency response experienced in the community.

f. Different ways of cooperation, communication and information means available.

\section{Focus Group Discussion}

A 'focus group discussion' has been conducted following the pilot survey to identify the new age-friendly features of the City and also to validate the identified features from literature review and pilot survey.

\section{Modified Fuzzy Delphi Method (MFDM)}

Modified Fuzzy Delphi method is the modified form of Fuzzy Delphi method which deals not only with the already identified criteria but also with the new ones as identified by experts during course of the expert opinion survey. The abbreviations used for the different levels of importance of a criterion are described on a seven point Likert scale as shown below in Table 1. If any expert's opinion is displayed as a triangular fuzzy number (li, mi, ui), the simplest method is to calculate the fuzzy average of experts' opinions i.e. ( $\Sigma$ li/n, $\Sigma m i / n, \Sigma u i / n)$. A triangular fuzzy spectrum for sevenpoint Likert scale on the significance of a criterion is as shown in Table 2 . The new identified criterion by any expert is also subjected to triangular fuzzy scoring (li, mi, ui) however scores $(0,0,0)$ if not identified by another expert. In the next step the difference between individual expert's opinion and the average of opinion of all the experts i.e. (li- $\left(\sum \mathrm{li} / \mathrm{n}, \mathrm{mi}-\Sigma \mathrm{mi} / \mathrm{n}, \mathrm{ui}-\sum \mathrm{ui} / \mathrm{n}\right)$ is statically analysed and sent to experts for their review and correction. This process is repeated until answers converge to a reasonable solution. Finally after fuzzy aggregation of experts' opinions the values are defuzzified and important criteria are retained through screening by a threshold value. There are several and complex methods for defuzzification. One of the simplest methods of defuzzification is to take average of triangular fuzzy numbers i.e. ( $\Sigma \mathrm{li} / \mathrm{n}+\sum \mathrm{mi} /$ 
$\left.\mathrm{n}+\sum \mathrm{ui} / \mathrm{n}\right) / 3$. This method can be extended by adding new experts and increasing number of iterations to get more accuracy in results.
This process not only retains the important criteria but also establishes a hierarchical structure with priority setting.

Table 1: Seven point Likert scale.

\begin{tabular}{|c|c|c|c|c|c|c|}
\hline $\begin{array}{c}\text { Extremely } \\
\text { Unimportant }\end{array}$ & Very Unimportant & Unimportant & $\begin{array}{c}\text { Moderately } \\
\text { Important }\end{array}$ & Important & Very Important & $\begin{array}{c}\text { Extremely } \\
\text { Important }\end{array}$ \\
\hline$(\mathrm{EU})$ & $(\mathrm{VU})$ & $(\mathrm{U})$ & $(\mathrm{MI})$ & $(\mathrm{I})$ & $(\mathrm{VI})$ & $(\mathrm{EI})$ \\
\hline
\end{tabular}

Table 2: Triangular fuzzy numbers in seven-point Likert scale.

\begin{tabular}{|c|c|c|c|c|c|c|}
\hline $\begin{array}{c}\text { Extremely } \\
\text { Unimportant }\end{array}$ & Very Unimportant & Unimportant & $\begin{array}{c}\text { Moderately } \\
\text { Important }\end{array}$ & Important & Very Important & $\begin{array}{c}\text { Extremely } \\
\text { Important }\end{array}$ \\
\hline$(0,0,0.1)$ & $(0,0.1,0.3)$ & $(0.1,0.3,0.5)$ & $(0.3,0.5,0.75)$ & $(0.5,0.75,0.9)$ & $(0.75,0.9,1)$ & $(0.9,1,1)$ \\
\hline
\end{tabular}

The Fuzzy Delphi method is a combination of the traditional Delphi Method with Fuzzy Set Theory. It was introduced by Kaufman and Gupta in 1988 (Kaufmann A \& Gupta MM [5]). Traditional Delphi method was first founded by Dalkey of RAND Corporation after introduction of Fuzzy sets by Lotfi Zadeh in 1965 (Zadeh LA [6]). However the ideas of Fuzzy sets were first envisioned by Max Black (Black [7]). The Delphi method is an interactive forecasting method which relies on the answers obtained from a panel of experts in two or more rounds until these answers convergence to correct answers. In traditional Delphi approaches, the quantification of experts' opinions will not fully reflect their thinking nature. Therefore applying fuzzy sets in Delphi helps the

Table 3: Comparison between Fuzzy Delphi and Delphi method. decision making process better. Furthermore, the error level is reduced by using fuzzy sets. The suitability of Fuzzy Delphi method over traditional Delphi method was explained by Ishikawa et al. in 1993 by comparing among the results obtained from Delphi method, Max-Min Fuzzy Delphi method and Fuzzy Delphi method via fuzzy integration (Ishikawa et al. [8]). The comparison between Delphi and Fuzzy Delphi technique is given below in the Table 3. The confidence of the model is increased further by 'Modified Fuzzy Delphi Method' as explained above and applied in this paper and is therefore proves to be the appropriate way for screening key criteria over simple Delphi technique.

\begin{tabular}{|c|c|c|}
\hline Method & Methodology & Weakness and strength \\
\hline Traditional Delphi Method & $\begin{array}{l}\text { Expert's responses are analysed statistically in each round } \\
\text { and communicated to them for their reviews to prepare } \\
\text { questionnaire for the next round. Responses are analyzed } \\
\text { again and this process is repeated until convergence. }\end{array}$ & $\begin{array}{l}\text { More time is spent is to collate expert opinions. } \\
\text { Cost is high because survey is repeated multiple } \\
\text { times. } \\
\text { The survey recovery rate is low. } \\
\text { Misinterpretation of expert's opinion becomes easy to } \\
\text { arrive at a consensus. } \\
\text { Anonymity among experts is maintained by this } \\
\text { method. }\end{array}$ \\
\hline Fuzzy Delphi Method & $\begin{array}{l}\text { Expert's responses are analysed statistically in each } \\
\text { round using Fuzzy numbers. A fuzzy statistical analysis is } \\
\text { done to find out the difference between individual value } \\
\text { and the mean value obtained from all the experts and is } \\
\text { communicated to experts for reviews. Experts' reviews } \\
\text { are analyzed and this process is repeated until outcome } \\
\text { converges to a reasonable solution. }\end{array}$ & $\begin{array}{l}\text { Reduces survey time and hence reduces cost by } \\
\text { reducing number of surveys } \\
\text { Increases questionnaire recovery rate. } \\
\text { the completeness and consistency of the group opinions as } \\
\text { it takes into account the fuzziness that cannot be avoided } \\
\text { during the survey process. }\end{array}$ \\
\hline
\end{tabular}

Modified Fuzzy Delphi Method algorithm includes the following steps:

a. Identifying an appropriate spectrum for fuzzification of linguistic expressions.

b. Assigning the level of importance by fuzzification.

c. Fuzzy aggregation of opinions of all the experts.

d. Statistical analysis of difference between individual opinion and average opinion of all the experts.

e. Re-verification and correction of opinions of previous round. f. Defuzzification of aggregated fuzzified values.

g. Selecting the threshold value and screening important criteria.

\section{Age-Friendly Criteria and Sub-Criteria}

An extensive literature review, pilot study, focus group discussion and interview with experts were conducted to identify age-friendly criteria and sub-criteria and categorize them under different category. The criteria and sub-criteria considered here for the study includes output, outcome and impact factors as recommended by WHO (WHO [9]). Though impact factors such as health and well-being are the outcome measures of long term 
achievement in age-friendliness of the community, considering only these may interpret its 'age-friendliness index'. Therefore output factors also referred to as intervening factors and outcome factors also referred to as short or medium term factors are more or less accountable.

\section{Independence level}

It is defined as the 'ability of a person to function independently, without depending on others, for livelihood or subsistence'. The availability of services and equipments and the enjoyment of a lifestyle that facilitates the choices of people with disability is the hall mark of independence. Therefore independence level of an individual is an indication of the quality of service rendered by his/ her immediate neighbourhood. Independence is identified as one of four domains of age-friendly environment by 14 focus groups among residents aged thirty five and above and community leaders from various areas (Lai et al. [10]). New skills acquired by learning through training in a positive social environment enhances selfconfidence and coping strategies, allowing older persons to stay independent (Steels [11]).

Housing options: Availability of houses in the community that is physically adapted so that a person can live in them as independently as possible. The international review of housing options and concepts highlighted that there should be adequate and appropriate housing options for elderly to promote their independence, choice and social contact (Davey [12]).

Transportation options: Elderly depend more on public transportation because of their retirement from driving. Therefore availability of different transportation options enhances the independent living capacity of a person. It gives a sense of independence and control over the lives of older people (Novak [13]). Examples of different transportation options available in a community are public transportation, specialized transportation and voluntary transport service etc.

Home adaptability: A person's own home carries required qualities of being easily modified to make it easier and safer for managing activities of daily living. Examples of home modification include widening doors, installing ramps, hand-held showers, and grab bars etc. Home modification brings independence with safety, security, dignity, accessibility and cost saving (The National Resource Center on Supportive Housing and Home Modification [14]).

Equipment usability: The available equipments that a disabled person requires to perform daily activities should be user friendly or posses the quality of being user friendly. This mobility option facilitated by use of use-friendly equipments enable the disabled person to become independent (Cook [15]). The degree to which the equipment becomes user friendly determines the level of independence of a person.

Accessibility: Accessibility refers to the characteristic of products, services, and facilities that enable people with a variety of disabilities to use them independently. Buildings and public places can be built with ramps along with stairs, making it possible for persons using wheel chairs to access them. Accessible public transportation increases independence and better freedom of choice (Crewe [16]). Access to housing, public places and information are important for maintaining independence among disabled and frail elderly.

Affordability: The costs of services or products shall be within one's financial capability. Elderly have a reduced income generation and a specific need. Therefore product or services required by elderly and the disabled should be affordable. Affordability of housing is a key factor for maintaining independence (Spillman [17]). The affordability can be achieved by Governmental interventions either in controlling the price of products of services or providing income generating activities specifically to elderly and the disabled.

\section{Social inclusion}

Social inclusion is the sense of belongingness experienced by a person to the community in which he/she lives by means of performing different activities while living in the community. Social inclusion are often referred to as "ability to participate" and would include social relations and emotional activities such as interacting with family, friends, and community members (Johner [18]). Social inclusion among older people is promoted by making communities more aging-friendly (Scharlach \& Lehning AJ [19]).

Proximity: It ensures reducing the physical and social distances between a person and his or her community which will reduce isolation, marginalisation and depression. This includes shared public spaces such as parks and libraries; integrated schools and classrooms and mixed income neighbourhoods and housing allowing people to have interactions (Mitchell \& Shillington R [20]).

Material well-being: Material well-being is an indicator of social inclusion (Huxley P [21]). It ensures that a person has material resources and safe housing necessary to allow him or her to participate fully in society (Saloojee [22]). Material well-being is measured through income, consumption patterns or assets.

Volunteering: It is the act of participating in the community with an aim of helping others by doing some activity, willingly and without being forced or paid to do it. It is immaterial of material resources that a person should posses to generate well-being in later life. European Union policies encourage volunteering as a tool to promote social inclusion in old age (Naegele G et al. [23]). The significance of organized voluntary work in societies is related to strong economic development (Wu H [24]). Due to cultural and historical differences, volunteering is deeply rooted in the countries of EU. While some countries (UK and Netherlands) have a long tradition of volunteering other countries give little importance to it (Naegele G et al. [23]).

Valued recognition: It includes conferring recognition and respect to individuals (Donnelly [25]). It generates well-being through encouragement, awards and honour.

Involvement and engagement: It ensures that a person should involve in different activities and has the right and necessary support to make decisions about his own health, housing and 
well being. Social inclusion means ensuring that the marginalized and those living in poverty have greater participation in decision making (Fitzduff [26]).

Family support: It ensures support provided to the needy member of the family by all other members at the time of need. It is an essential component of social inclusion of elderly and the disabled at time when these section of people experiences absence of social support from the community.

\section{Well-being}

It is the state of feeling comfortable, healthy and happy. Wellbeing is a key feature of age-friendly frame work (Steels [11]).

Physical well-being: Physical well-being involves exercising, good nutrition, and of course making healthy lifestyle choices. Remaining active is an important task of incorporating wellbeing into everyday activities. Age-friendly community provides a secure environment which strongly affects physical health and well-being of people.

Social well-being: Social wellbeing measures the degree of a person's relationships with others in terms of how that person interacts, communicates, and socialises with other people in the community. Age-friendly community is a global health promotion strategy that address the importance of creating physical and social environment that support the well-being of older adults (Rootman [27]).

Emotional Wellness: It refers to a person's positive attitude, high self-esteem, and a strong sense of self and has the ability to share his own feelings with others in the community in a constructive way. Age-friendly community provides a secure environment which strongly affects emotional well-being of people (WHO [28]).

Environmental well-being: Environmental well-being enables a person to understand the impact of one's interaction with nature and surrounding environment, and taking action to protect the world in a constructive way. One of the features of an age-friendly community is a pleasant and clean environment (Smith [29]).

Spiritual well-being: A sense of peace and contentment stemming from an individual's involvement in spiritual aspects of life. Age-friendly environment enhances opportunities for physical, social and spiritual well-being (Plouffe LA et al. [30])

\section{Safety and security}

An age-friendly environment reduces the risk of falls and prevents the abuse and neglect of vulnerable older people by increasing the safety and security of the natural and built environments (WHO). Outdoor spaces and buildings, transportation, and housing are key features of city's physical environment which have a strong influence on personal mobility, safety from injury, security from crime, health behaviour and social participation (WHO [31]). Therefore proper design of this physical environment would be able to address the aging related issues.

Land use: Safety of a community depends on type of land use and its surroundings. For example a mixed land use enhances safety by protecting from theft and crime. Modern city-planning techniques encouraging the segregation of land uses have resulted in urban sprawl and unsafe suburban environments that are not advisable for walking (Sideris LA [32]).

Transportation safety: Transportation safety is concerned with the protection of life and property through proper zoning, regulation, management and development of technology for all forms of transportation. When safe driving is no longer possible for older adults, alternative transportation options which are safe must be available which will also benefit other users, particularly those with disabilities (Dickerson et al. [33]).

Indoor safety: Fall is the major risk inside a home as compared to other risks like fire accident, electrical accidents etc. particularly to the elderly people. Examples of indoor safety measures are nonslip floor, sufficient lighting, grab bars, and handrails etc. Home safety is one of the needs of elderly for their healthy living (Plouffe L \& Kalache A [34]).

Outdoor safety: Outdoor safety is promoted by good amount of street lighting, police patrols and awareness creation through community education (Gawron G \& Adamek RP [35]).

\section{Information and communication}

Provision of information and communication to a community allows people to stay up to date by obtaining appropriate and relevant information they need to manage their lives by taking action on important information about public health and social services. With awareness creation, products, services, communication messages and approaches can be developed to ensure that people, especially seniors have access to materials and messages intended to support them. A community that ensures people to age well should provide appropriate information in order to ensure people stay healthy, active and secure enabling to participate fully in their community (Everingham et al. [36]).

Information ground: Information grounds are environments in which individuals gather for some activity involving social interactions, through which information is shared. There are also other sources such as local media and newspapers, public posters and notices through which information reaches the community (Everingham et al. [36]).

Mobile networking: The information and communication reaches the community through mobile networking. People with disabilities or older people can use mobile technology to get access to some services vital for them at any time for their security and autonomy (Abascal J \& Civit A [37]).

Internet services: The information reaches the community through internet services. Use of the internet as a source of information has been found to decline rapidly with age (Everingham et al. [36]).

\section{Results and Discussion}

Data obtained from expert's opinion were fuzzified using triangular fuzzy numbers as given in Table 2. Average of expert's 
opinion is calculated to get the fuzzified average value. Then obtained value is defuzzified using the average of triangular fuzzy numbers. The threshold value taken depends on decision maker's choice and local context. This value is taken as 0.52 for this study which is the average of the three triangular fuzzy numbers for moderately important level i.e. $(0.3+0.5+0.75) / 3$. The results obtained are given below in the Table 4. Results show that all criteria initially taken and identified during the course of survey hold good for further study on age-friendliness of the community. Further the results show the hierarchy of importance of criteria and sub-criteria which can be considered for priority setting in Governmental interventions.

Table 4: Fuzzification and defuzzification of linguistic expressions for the screening of important criteria.

\begin{tabular}{|c|c|c|c|c|c|c|c|}
\hline \multirow[t]{2}{*}{ Criteria and Sub criteria } & \multicolumn{4}{|c|}{ Gathering expert opinion in seven point Likert scale } & \multirow[t]{2}{*}{$\begin{array}{l}\text { Opinion's } \\
\text { mean }\end{array}$} & \multirow[t]{2}{*}{$\begin{array}{l}\text { Crisp } \\
\text { value }\end{array}$} & \multirow[t]{2}{*}{ Results } \\
\hline & Expert 1 & Expert 2 & Expert 3 & ...Expert 26 & & & \\
\hline Independence & $0.9,1,1$ & $0.9,1,1$ & $0.9,1,1$ & & $.82, .95, .99$ & 0.92 & Accepted \\
\hline Social inclusion & $0.9,1,1$ & $.5, .75, .9$ & $.75,9,1$ & & $.65, .81, .92$ & 0.79 & Accepted \\
\hline Well being & $.5, .75, .9$ & $.3, .5, .75$ & $.75,9,1$ & & $.66, .82, .92$ & 0.8 & Accepted \\
\hline Information and communication provision & $0.9,1,1$ & $.5, .75, .9$ & $0.9,1,1$ & & $.81, .93, .98$ & 0.85 & Accepted \\
\hline Safety and security & $0.9,1,1$ & $0.9,1,1$ & $0.9,1,1$ & & $.79, .92, .98$ & 0.91 & Accepted \\
\hline Independence & $0.9,1,1$ & $0.9,1,1$ & $0.9,1,1$ & & $.82, .95, .99$ & 0.92 & Accepted \\
\hline Housing options & $.75, .9,1$ & $.5, .75, .9$ & $.75,9,1$ & & $.56, .74, .88$ & 0.73 & Accepted \\
\hline Transportation options & $0.9,1,1$ & $.75, .9,1$ & $.5, .75, .9$ & & $.61, .79, .92$ & 0.77 & Accepted \\
\hline Home adaptability & $0.9,1,1$ & $0.9,1,1$ & $.5, .75, .9$ & & $.58, .74, .87$ & 0.73 & Accepted \\
\hline Equipment usability & $.75, .9,1$ & $.75, .9,1$ & $.5, .75, .9$ & & $.61, .78, .89$ & 0.76 & Accepted \\
\hline Accessibility & $.5, .75, .9$ & $.3, .5, .75$ & $.5, .75, .9$ & & $.63,80, .92$ & 0.78 & Accepted \\
\hline Affordability & $0.9,1,1$ & $.5, .75, .9$ & $.75,9,1$ & & $.67, .83, .94$ & 0.81 & Accepted \\
\hline Social inclusion & $0.9,1,1$ & $.5, .75, .9$ & $.75, .9,1$ & & $.65, .81, .92$ & 0.79 & Accepted \\
\hline Proximity & $.1, .3, .5$ & $.5, .75, .9$ & $.3, .5, .75$ & & $.58, .76, .89$ & 0.74 & Accepted \\
\hline Material well being & $.3, .5, .75$ & $.5, .75, .9$ & $.3, .5, .75$ & & $.47, .67, .83$ & 0.66 & Accepted \\
\hline Volunteering & $0.9,1,1$ & $0.9,1,1$ & $.3, .5, .75$ & & $.47, .66, .82$ & 0.65 & Accepted \\
\hline Valued recognition & $.5, .75, .9$ & $.3, .5, .75$ & $.5, .75, .9$ & & $.57, .73, .86$ & 0.72 & Accepted \\
\hline Involvement and engagement & $0.9,1,1$ & $.5, .75, .9$ & $.5, .75, .9$ & & $.69, .85, .94$ & 0.83 & Accepted \\
\hline Family support & $.5, .75, .9$ & $0.9,1,1$ & $.5, .75, .9$ & & $.71, .87, .95$ & 0.85 & Accepted \\
\hline Well being & $.5, .75, .9$ & $.3, .5, .75$ & $.75, .9,1$ & & $.66, .82, .92$ & 0.8 & Accepted \\
\hline Physical & $0.9,1,1$ & $.3, .5, .75$ & $.75, .9,1$ & & $.73, .88, .96$ & 0.86 & Accepted \\
\hline Social & $.75, .9,1$ & $0.9,1,1$ & $0.9,1,1$ & & $.75, .89, .97$ & 0.87 & Accepted \\
\hline Environmental & $0.9,1,1$ & $0.9,1,1$ & $.5, .75, .9$ & & $.60, .78, .90$ & 0.76 & Accepted \\
\hline Emotional & $.75, .9,1$ & $.3, .5, .75$ & $0.9,1,1$ & & $.69, .85, .94$ & 0.83 & Accepted \\
\hline Spiritual & $0.9,1,1$ & $.3, .5, .75$ & $.75,9,9$ & & $.50, .68, .83$ & 0.67 & Accepted \\
\hline Safety and security & $0.9,1,1$ & $0.9,1,1$ & $0.9,1,1$ & & $.79, .92, .98$ & 0.91 & Accepted \\
\hline Landuse safety & $.5, .75, .9$ & $.5, .75, .9$ & $.5, .75, .9$ & & $.59, .78, .91$ & 0.76 & Accepted \\
\hline Transportation safety & $0.9,1,1$ & $.5, .75, .9$ & $.75, .9,1$ & & $.69, .85, .94$ & 0.83 & Accepted \\
\hline Indoor safety & $0.9,1,1$ & $.5, .75, .9$ & $.3, .5, .75$ & & $.73, .89, .97$ & 0.86 & Accepted \\
\hline Outdoor safety & $0.9,1,1$ & $0.9,1,1$ & $0.9,1,1$ & & $.77, .90, .97$ & 0.88 & Accepted \\
\hline $\begin{array}{c}\text { Information and communication } \\
\text { provision }\end{array}$ & $0.9,1,1$ & $.5, .75, .9$ & $0.9,1,1$ & & $.81, .93, .98$ & 0.85 & Accepted \\
\hline Information ground & $0.9,1,1$ & $0.9,1,1$ & $.3, .5, .75$ & & $.54, .72, .86$ & 0.71 & Accepted \\
\hline Mobile networking & $0.9,1,1$ & $.5, .75, .9$ & $.75, .9,1$ & & $.64, .81, .93$ & 0.79 & Accepted \\
\hline Internet services & $0.9,1,1$ & $.5, .75, .9$ & $0.9,1,1$ & & $.59, .77, .89$ & 0.75 & Accepted \\
\hline
\end{tabular}


The value for importance level of all criteria and sub-criteria are above 0.52 which signifies that all criteria and sub-criteria initially taken and identified during course of survey are accepted for evaluating 'Age-Friendliness Index', AFI of the community. The threshold value taken depends upon the researcher's choice and the local context.

\section{Computational Approach for 'Age-Friendliness Index' of Communities}

After the selection process by Modified Fuzzy Delphi method as described above is over local weights will be assigned to these selected criteria and sub-criteria derived from Analytical Hierarchy Process by pair-wise comparison. Then corresponding global weights Wi of sub-criteria will be calculated by multiplying local weights of criteria with the local weights of sub-criteria. Fuzzy quantified output values of these sub-criteria will be calculated for different communities by Fuzzy Logic Controller (FLC) systems. If the sub-criterion function is denoted by $\mathrm{Xi}$, and corresponding fuzzy performance output value is denoted by $\mathrm{f}(\mathrm{Xi})$, then the 'agefriendliness index' of communities will be $\sum \mathrm{Wix} f(\mathrm{Xi})$.

\section{The Conclusion and Future Work}

This study used five criteria namely 'independent living', 'social inclusion', 'well-being', 'safety and security' and 'information and communication provision' and 24 sub criteria for evaluating agefriendliness of a community. The results obtained showed that independent living capability of a person is the most important criteria followed by safety and security of the community environment to meet the desired level age-friendliness although other criteria are more or less accountable. Further 'Agefriendliness index' which will be developed with the help of weights assigned to these criteria and sub-criteria and further subjected to their fuzzy performance output values will help in classifying communities according to the level of 'age-friendliness' and in turn help in setting priorities in governmental intervention. Further the identified features under each criteria and sub-criteria and 'age-friendliness index' so developed will also help in formulating policies and recommendations for future age-friendly cities.

\section{References}

1. WHO (2007b) Global age-friendly cities: a guide (W. H. Organization Ed.) WHO, Geneva, Switzerland.

2. Ostroff E (2007) Universal design: An evolving paradigm pp. 1-11.

3. Government of Queensland (2017) Queensland: an age-friendly community: Government of Queensland pp. 1-21.

4. Buffel T, Phillipson C, Scharf T (2012) Ageing in urban environments: Developing 'age-friendly' cities. Critical Social Policy 32(4): 597-617.

5. Kaufmann A, Gupta MM (1988) Fuzzy mathematical models in engineering and management science. North-Holland, Amsterdam, New York, USA.

6. Zadeh LA (1965) Fuzzy Sets. Information and Control 8(3): 338-353.

7. Black M (1937) Vagueness. an exercise in logical analysis. Philosophy of Science 4(4): 427-455.
8. Ishikawa A, Amagasa M, Shiga T, Tomizawa G, Tatsuta R, et al. (1993) The Max-Min Delphi method and fuzzy Delphi method via fuzzy integration. Fuzzy Sets and Systems 55(3): 241-253.

9. WHO (2016) Measuring the age-friendliness of cities, Japan, P. 128.

10. Lai M, Lein S, Lau S, Lai M (2016) Modeling age-friendly environment, active aging, and social connectedness in an emerging asian economy. Journal of Aging Research 1-14.

11. Steels S (2015) Key characteristics of age-friendly cities and communities: A review. Cities 47: 45-52.

12. Davey J, Joux VD, Nana G, Arcus M (2004) Accommodation options for older people in Aotearoa/New Zealand, New Zealand, pp. 1-202.

13. Novak M (2016) Issues in ageing ( $3^{\text {rd }}$ edn),Taylor \& Francis Group, New York, USA.

14. The National Resource Center on Supportive Housing and Home Modification. (2003) Home modification resource guide. University of Southern California Andrus Gerontology Center, Los Angeles, California, USA, pp. 1-91.

15. Cook AM, Polgar JM (2015) Assistive technologies, principles and practice, Elsevier, Missouri, USA.

16. Crewe NM, Zola IK (2001) Independent living for physically disabled people, USA.

17. Spillman BC, Biess J, MacDonald G (2012) Housing as a platform for improving outcomes for older renters.

18. Johner R (2011) Understanding disability, inclusion and social activity participation.

19. Scharlach AE, Lehning AJ (2013) Ageing-friendly communities and social inclusion in the United States of America pp. 33(1): 110-136.

20. Mitchell A, Shillington R (2002) Poverty, inequality and social inclusion.

21. Huxley P (2015) Introduction to "indicators and measurement of social inclusion". Social Inclusion 3(4): 50-51.

22. Saloojee A (2003) Social inclusion, anti-racism and democratic citizenship.

23. Naegele G, Schnabel E, Maat JWVD, Kubicki P, Chiatti C, et al. (2010) Measures for social inclusion of the elderly: The case of volunteering. Eurofound, pp. 1-38.

24. Wu H (2011) Social impact of volunteerism pp. 1-23.

25. Donnelly P, Coakley J (2002) The role of recreation in promoting social inclusion.

26. Fitzduff M (2007) Measuring social inclusion and cohesion-the challenges Paris, France, pp. 1-12

27. Rootman I, Dupere S, Pederson A, O’Neill M (2012) Health promotion in Canada: critical perspectives on practice.

28. WHO (2007a) Global age-friendly cities: a guide: WHO, Geneva, Switzerland, pp. 1-76.

29. Smith AE (2009) Ageing in urban neighbourhoods: place attachment and social exclusion. Great Britain.

30. Plouffe LA, Garon S, Brownoff J,Eve D, Foucault ML, et al. (2013) Advancing age-friendly communities in Canada: community implementation guide, pp. 11-24.

31. WHO (2007) Age-friendly environments. Ageing and life-course.

32. Sideris LA (2006) Is it safe to walk? neighborhood safety and security considerations and their effects on walking. Journal of Planning Literature 20(3): 219-232. 
33. Dickerson AE, Molnar LJ, Eby DW, Adler G, Bedard M, et al. (2007) Transportation and aging: a research agenda for advancing safe mobility. The Gerontologist 47(5): 578-590.

34. Plouffe L, Kalache A (2010) Towards global age-friendly cities: determining urban features that promote active aging. Journal of Urban Health: Bulletin of the New York Academy of Medicine 87(5): 733-739.

35. Gawron G, Adamek RP (2015) The idea of age-friendly cities and communities as a response to the challenges of contemporary demographic changes. Athens Institute for Education and Research, Athens, Greece.

36. Everingham J, Petriwskyj A, Warburton J, Cuthill M, Bartlett H (2009) Information provision for an age-friendly community. Ageing International 34(1-2): 79-98.

37. Abascal J, Civit A (2000) Mobile communication for people with disabilities and older people: new opportunities for autonomous life, Italy.

\section{Your subsequent submission with Crimson Publishers will attain the below benefits}

- High-level peer review and editorial services

- Freely accessible online immediately upon publication

- Authors retain the copyright to their work

- Licensing it under a Creative Commons license

- Visibility through different online platforms

- Global attainment for your research

- Article availability in different formats (Pdf, E-pub, Full Text)

- Endless customer service

- Reasonable Membership services

- Reprints availability upon request

- One step article tracking system 